\title{
CORPORATE CAPITAL BUDGETING DECISIONS AND INFORMATION SHARING
}

\author{
Abigail S. Hornstein \\ Wesleyan University \\ 238 Church Street \\ Middletown, CT 06459 \\ ahornstein@wesleyan.edu \\ MinYUAN ZHAO \\ University of Michigan \\ 701 Tappan Street \\ Ann Arbor, MI 48109 \\ myzhao@umich.edu
}

Firms must overcome agency and information asymmetry problems to make efficient corporate capital budgeting decisions; this is particularly true for firms with multiple units dispersed across geographic locations. Internal communication and coordination may therefore be crucial in reducing information asymmetry and achieving efficient resource allocation. We examine the relationship between corporate capital budgeting decisions and the degree of internal information sharing using a dataset of 342 U.S. firms from 1993 to 2002. Information sharing is measured by the internal linkages observed in firms' research and development activities worldwide. The efficiency of a firm's capital budgeting decisions is measured by the deviation of the firm's estimated marginal $q$ from the theoretical tax-adjusted benchmark. We observe a significant relationship between value-enhancing capital budgeting decisions and stronger internal linkages. Specifically, corporate overinvestment is significantly reduced with better information sharing across units. All results are robust to firm-and industry-level controls.

We thank Bernard Yeung, Wilbur Chung, Masami Imai, Cristian Dezso, Artyom Durnev, and seminar participants at Wesleyan University, Western Economic Association, Academy of Management, the Financial Management Association, and the International Industrial Organization Conference for helpful comments. We also thank the journal editors and two anonymous reviewers for comments and suggestions. Hornstein thanks the Mellon Foundation for financial support and J.J. Feigenbaum for excellent research assistance. All errors remain our own. 


\section{INTRODUCTION}

There are many reasons why firms may not invest at optimal levels. Firms with more agency and informational asymmetry problems, for example, make less efficient capital budgeting decisions (Durnev et al., 2004; Greene et al., 2009). Information asymmetry problems may be particularly acute for large multi-unit organizations, which are often geographically dispersed and managed with relative autonomy. With distance and organizational boundaries being significant barriers of information transfer (Kogut and Zander, 1992; Jaffe et al., 1993), under- or overinvestment by the firm may result from inefficient communication and coordination across various units. On the one hand, if complementary assets inside the firm are not properly utilized, valuable investment opportunities may be overlooked. On the other hand, repetitive or inefficient investments may occur when managers are unaware of resources available in other parts of the organization.

Note that this is not only a problem of larger margins of error due to the lack of precise information; it can lead to consistent biases if managers do not take such communication inefficiency into consideration when making investment decisions. For example, in a multinational firm with horizontally diversified subsidiaries, managers who are unaware of resources available in other parts of the firm-and are not conscious of their unawareness-may consistently overinvest from the shareholder's perspective.

As market competition centers more and more on the development of intangible assets, the ability to combine and recombine existing knowledge represents the firms' key competitive advantage (Kogut and Zander, 1992; Henderson and Cockburn, 1994). When crucial resources within the firm become increasingly intangible, how to mobilize these resources may have a significant impact on managers' investment behavior. In this paper, we examine whether efficient corporate capital budgeting decisions are associated with intrafirm coordination and collaboration in developing intangible assets, after controlling for other relevant firm characteristics. We expect that, ceteris paribus, firms with more internal information sharing may make more efficient corporate budgeting decisions, particularly in organizations dispersed across many locations.

Efficiency of capital budgeting decisions is examined from the perspective of firm value maximization, using marginal Tobin's $q$, the ratio of the marginal change in market value to the contemporaneous marginal change in assets. Theoretically, with declining returns to investment, firms should continue to invest until the marginal return of any further investment approaches zero from above, that is, when 
the marginal gain to the firm equals the marginal cost of investment. The deviation of a firm's estimated marginal $q$ from the theoretical optimal value of marginal $q$ can serve as a reverse indicator of the efficacy of a firm's capital budgeting decisions. We consider a firm underinvesting if it stops investing when its estimated marginal $q$ is still above the theoretical optimal level and a firm overinvesting if it invests when its estimated marginal $q$ is already below the theoretical optimal level.

Thus, we apply a two-stage empirical framework. In the first step we estimate marginal $q$ for each firm as a coefficient in a regression. In the second stage we use the estimated marginal $q$ 's to form the dependent variable, the deviation of the estimated marginal $q$ from the benchmark marginal $q$, which is then regressed on measures of internal information sharing and control variables. We examine the separate groups of underand overinvesting firms to investigate whether there is a consistent relationship between efficient capital budgeting and the presence of information sharing channels, and whether these relations are similar in the under- and overinvesting samples.

We use four alternative measures of internal information sharing, utilizing information on firms' patenting activities. We admit that these measures are not perfect substitutes for each other, and that each measure incorporates more dimensions than internal information sharing, which is a concept that is intrinsically difficult to quantify. The purpose of using four alternatives is to identify consistent relationships not caused by a specific proxy. First, the self-citation ratio, defined as the percentage of forward citations that occur within the firm boundary, represents internalized knowledge transfers (Trajtenberg et al., 1997; Hall et al., 2002) and thus the degree to which firms take full advantage of their internal resources at various locations. Second, the nonlocal self-citation ratio reveals the percentage of self-citations to patents developed by researchers in other locations. Because information asymmetry problems are most challenging for multilocation firms, this ratio reflects the strength of internal communications channels across branches or subsidiaries. Third, having researchers from different parts of the world collaborate on the same project may signal the firm's strong interunit coordination and also promote future knowledge flows within the firm (Zhao, 2006; Lahiri, 2010; Alcácer and Zhao, 2011). Hence, we calculate the percentage of patents resulting from cross-regional collaborations and use it as a measure of internal linkages. Finally, we use the percentage of self-citations imposed by patent examiners to proxy for the lack of internal information sharing. Although an inventor may choose not to cite a competitor's patents for strategic reasons, failing to cite the same firm's prior art is probably due to ineffective 
communication and coordination inside the firm. Therefore, we use the percentage of externally imposed self-citations to measure the information barriers in the organization, a countermeasure of information sharing.

A sample of 342 U.S. manufacturing firms that filed patents during the period 1993 to 2002 is studied herein. To the extent that research and development $(R \& D)$ is usually one of the most centralized functions in a firm, internal coordination and communication may be particularly important to firms that engage actively in R\&D. Although our sample selection criterion may lead to an upward bias in the estimation of marginal $q$ and the estimation of information sharing, we do not believe that these firms' capital budgeting decisions necessarily differ systematically from their non-R\&D-intensive peers. We will discuss this point further in the empirical section.

Our empirical results support the theoretical arguments. In general, more efficient capital budgeting decisions are associated with stronger internal linkages, and the effect is positively moderated by the number of locations where the firm has R\&D activities. The rest of the paper proceeds as follows. In Section 2, we discuss the theoretical rationale for a relationship between efficient capital budgeting and internal information sharing. The measures of investment efficiency and internal coordination are outlined in Section 3. The data and econometric methods are described in Section 4. In Section 5 we present and analyze the empirical results and their implications. In Section 6 we present and analyze robustness tests using average Tobin's $Q$ as the dependent variable. Section 7 concludes.

\section{THEORETICAL ANAlysis}

\subsection{FIRM ORGANIZATION AND INFORMATIONAL ASYMMETRY}

Firms that face agency and informational asymmetry problems make less efficient capital budgeting decisions (Durnev et al., 2004; Greene et al., 2009) due to both intrafirm and interfirm conditions. Internally, to make value-enhancing capital budgeting decisions, managers must possess sufficient information about the organization, and their interests must be aligned with those of the shareholders. Given that investors and management may have asymmetric information, complex corporate structures also may shield managers who pursue agency behavior. For example, managers could deliberately mis-invest to entrench themselves (Shleifer and Vishny, 1989), overinvest for empire building (Jensen, 1986; Morck and Yeung, 1992), or be excessively risk-averse to protect personal interests (John et al., 2008). 
Externally, to the extent that investors perceive there to be agency or informational asymmetry problems, financing might be priced at a premium (Myers and Majluf, 1984). The resultant liquidity constraint could cause a firm to reduce the scale of its investment activity (Himmelberg et al., 2002). Such concerns are particularly important for multi-unit firms, which tend to have more complex organizational structures and present greater agency and information asymmetry problems to managers and investors (e.g., Graham et al., 2002).

A notable difficulty in multi-unit firms is that not all information can be codified and transferred across units (Kogut and Zander, 1992; Szulanski, 1996). The difficulty can be significantly compounded if the units are located across distances, which could limit the interpersonal interactions needed for knowledge transfer and interpretation (Jaffe et al., 1993; Audretsch and Feldman, 1996). As a result, two types of inefficiencies may occur. First, when a decision is made at one location, the manager may be uninformed of the resources available in other parts of the firm. Fully aware of these information constraints, the manager has to choose an investment level based on an incomplete information set, which produces a larger variance around the optimal. The second inefficiency could arise from managers' ignorance or underestimation of such information barriers. That is, the manager may be uninformed of what is happening in other parts of the firm, and in addition also be unaware of the incompleteness of their information set. As a result, the manager may systematically overinvest in duplicative assets or underinvest in complementary assets.

Although diversified firms in general face greater challenges in internal communication and coordination, some of them possess unique organizational capabilities that enable them to overcome such challenges and make more effective investment decisions. For example, multinational firms have long been recognized as a dispersed innovation network, with the capacity to assimilate, generate, and integrate knowledge on a global basis (Buckley and Casson, 1976; Bartlett and Ghoshal, 1990). Firms also frequently adjust their internal allocation of resources depending on the local environments. Desai et al. (2004) suggest that multinational firms appear to increase their internal borrowing in countries with underdeveloped capital markets or weak creditor rights. Feinberg and Gupta (2004) find evidence that U.S.-headquartered multinational firms respond to high risks in the host countries by increasing the extent of internal transactions among subsidiaries. These organizational features may explain why some multinational firms have stronger performance despite the challenges of coordinating subsidiaries. Thus, understanding the sources of firm heterogeneity is important to an analysis of organizational performance. 
In this study, we examine a particular dimension of firm heterogeneity: the efficiency of corporate budgeting decisions in multi-unit firms. Greene et al. (2009) observe that more efficient capital budgeting is strongly associated with multinationality, but do not provide an explanation for why this is the case. This paper intends to identify a specific mechanism behind the efficiency, that is, whether the efficiency of firms' capital budgeting decisions is associated with the coordination mechanisms that allow firms to alleviate agency or information asymmetry problems.

\subsection{MECHANISMS OF INTERNAL INFORMATION SHARING}

In a large, dispersed organization, business units or divisions are often exposed to idiosyncratic challenges and opportunities in their respective industries or geographic locations. They often have their own agendas and interests, which may or may not be consistent with the firm's overall strategic goals. Firms therefore have reason to establish various formal and informal channels for internal coordination (Gupta and Govindarajan, 2000) to reduce coordination barriers and any related dissonance within the firm.

This is crucial for efficient corporate capital budgeting, which requires managers to use resources effectively at the organization level. Given the intangible nature of information sharing, it is almost impossible to capture the full spectrum of intrafirm communication and coordination. However, for firms that engage in active innovation, their patenting activities leave a valuable "paper trail" that can be used to examine the otherwise invisible internal linkages (Jaffe et al., 2000). Because many firms conduct simultaneously R\&D in multiple locales, and innovation is increasingly important for market competition, we believe that information sharing in firms' $R \& D$ activities is a good representation of the overall levels of communication and coordination inside the corporation.

One mechanism of internal information sharing is knowledge flows inside the organization, especially across units or geographic locations. Hall et al. (2005) suggest that internalized knowledge transfers can lead to corporate competitive advantage and thus higher firm value. Firms with good coordination mechanisms should be able to identify and build on internal technologies better and faster than competitors. For example, Zhao (2006) suggests that the ability to integrate internal technologies enables multinational firms to appropriate value from $R \& D$ even in countries with weak intellectual property rights protection. Similar findings have been identified for firms conducting R\&D in highly competitive technology clusters (Alcácer and Zhao, 2011). 
The second mechanism that we identify is interpersonal collaboration. Despite the development of information technologies, knowledge spillovers remain locally constrained (Jaffe et al., 1993); even knowledge transfer inside the firm boundary has proved to be challenging without the right mechanisms in place (Kogut and Zander, 1992; Szulanski, 1996). Interpersonal relationships have long been considered an important mechanism of information sharing. Cockburn and Henderson (1998) use joint publications between scientists in pharmaceutical firms and researchers in publicly funded universities to measure the connectedness of firms to the external environment. Similarly, Lahiri (2010) uses co-patenting by semiconductor scientists as a measure of intrafirm linkages. Presumably, having researchers from different countries collaborate on the same project not only signals the firm's strong interunit coordination but also promotes future knowledge flows within the firm (Singh, 2008).

Based on the above discussion, we argue that collaboration and knowledge flow within firms can encourage communication and coordination, thus improving the effectiveness of corporate budgeting decisions in large organizations. ${ }^{1}$ In the next section, we describe the empirical setup and the key variables used to test this relationship.

\section{MODEL AND EMPIRICAL METHODOLOGY}

\subsection{MARgINAL $q$}

Firms derive incremental value from each investment they make, and if the capital markets are well informed, this change in firm assets should be reflected in contemporaneous changes in the firm's market value. Due to diminishing returns to investment, the firm eventually may have a marginal investment project whose incremental value exactly equals the incremental cost. Optimally, the firm should stop right here.

Marginal $q$ is defined as the ratio of the unanticipated incremental firm market value divided by the contemporaneous marginal investment. Therefore, the value-maximizing capital budgeting decision would yield a marginal $q$ of 1.0: a positive (negative) deviation of a firm's estimated marginal $q$ from 1.0 indicates under- (over-) investment. Of course, exogenous factors such as taxes may affect the capital budgeting

1. Note that in this study we focus on the effectiveness of corporate capital budgeting decisions, which often, but not always, contribute to overall firm performance and profitability. The link between internal coordination and profitability is less straightforward. For example, some firms may promote competition, rather than coordination, among subsidiaries with volume and performance-based incentives, which may lead to inefficient use of resources but better profitability. 
process such that the optimal benchmark marginal $q$ may differ from the theoretical benchmark of 1.0.

Note that this is a different concept from Tobin's $Q$ (or average $Q$ ), which measures market perceptions of the firm's value. In the absence of agency problems, internal information sharing can have the direct effect of guiding firms to assess their existing assets before making investment decisions, thus avoiding under- or overinvestment, but only has a secondary effect on the quality or profitability of an investment. Therefore, we believe that marginal $q$ is a more appropriate measure of corporate capital budgeting for the purpose of this study. For robustness checks, we also examine the effect of internal information sharing on the estimated average $Q$.

The methodology to calculate marginal $q$ was developed by Durnev et al. (2004) and was extended by Greene et al. (2009). The marginal $q$ of firm $i$ can be defined as:

$$
\dot{q}_{i}=\frac{V_{i, t}-E_{t-1} V_{i, t}}{A_{i, t}-E_{t-1} A_{i, t}}=\frac{V_{i, t}-V_{i, t-1}\left(1+\hat{r}_{i, t}-\hat{d}_{i, t}\right)}{A_{i, t}-A_{i, t-1}\left(1+\hat{g}_{i, t}-\hat{\delta}_{i, t}\right)},
$$

where $V_{i, t}$ is the market value of firm $i$ at time $t$, and $A_{i, t}$ is the total assets of firm $i$ at time $t$. $E_{t-1}$ is the expectations operator, which uses all information available to the firm at time $t-1$. We substitute for the expectations operator using $\hat{r}_{i, t}$, the expected return from owning the firm and disbursements to investors; $\hat{d}_{i, t}$, the expected level of disbursements from the firm (dividends, share repurchases, and interest expenses); $\hat{g}_{i, t}$, the rate of expected expenditures on capital goods; and $\hat{\delta}_{j, t}$, the expected rate of depreciation of the firm's assets. See the appendix for details of how we estimate the firm's value $(V)$ and assets $(A)$.

Rearranging and simplifying equation (1), we derive the empirical specification as:

$$
\frac{\Delta V_{i, t}}{A_{i, t-1}}=\beta_{0, i}+\beta_{1, i} \frac{\Delta A_{i, t}}{A_{i, t-1}}+\beta_{2, i} \frac{V_{i, t-1}}{A_{i, t-1}}+\beta_{3, i} \frac{D_{i, t-1}}{A_{i, t-1}}+\delta_{t} P_{t}+u_{i, t},
$$

where $D_{i, t-1}$ (or $d_{i, t} V_{i, t-1}$ ) is disbursements to investors, including dividends, share repurchases, and interest expenses. A series of year fixed effects, $P_{t}$, are also included to reflect cyclical economic factors that may affect all firms. The coefficient $\beta_{1, i}$ is firm $i$ 's marginal $q$.

Because all four coefficients in equation (2) may reflect firm heterogeneity, they are treated as random and estimated in the random coefficient model as $\hat{\beta}_{j}=\beta+v_{i, j}$, where $i$ indicates firm (1..I), and $j$ denotes the coefficient number $(0 \ldots 3)$. This yields an estimate and 
variance for each coefficient, $\hat{\beta}_{j}$, and a series of firm-specific estimates of each coefficient, $\hat{\beta}_{i, j}$. The estimated coefficients are then used to form the dependent variables for the second-round testing, which will be explained in Section 3.2.

Admittedly, the estimated marginal $q$ (i.e., $\hat{\beta}_{1, i}$ ) is susceptible to noise in the data. For example, the change in investment may be misestimated due to accounting errors, and the change in firm value may reflect new information about prior investments. Moreover, while theory suggests that marginal $q$ should be estimated using continuous time data in order to properly isolate the marginal investment made by a firm, the accounting data used to estimate marginal $q$ is never continuous.

One caveat of marginal $q$ calculation stems from tax considerations. As explained by Durnev et al. (2004), the marginal investor in a firm may face capital gains taxes, $T_{C G}$, upon selling shares in the firm, and personal income taxes, $T_{D}$, upon receiving dividends from the firm. Thus, instead of equation (1), the marginal $q$ to such an investor should be $\frac{\left(1-T_{C G}\right)\left(V_{i, t}-E_{t-1} V_{i, t}\right)}{\left(1-T_{D}\right)\left(A_{i, t}-E_{t-1} A_{i, t}\right.}$. Using this definition, we obtain equation (3), which is analogous to equation (2).

$\frac{\Delta V_{i, t}}{A_{i, t-1}}=\beta_{0, i}+\dot{q}_{i, t} \frac{1-T_{D}}{1-T_{C G}} \frac{\Delta A_{i, t}}{A_{i, t-1}}+\beta_{2, i} \frac{V_{i, t-1}}{A_{i, t-1}}+\beta_{3, i} \frac{D_{i, t-1}}{A_{i, t-1}}+\delta_{t} P_{t}+u_{i, t}$.

Thus, the estimated marginal $\hat{q}_{i}$ will be $\dot{q}_{i} \cdot\left(\frac{1-T_{D}}{1-T_{C G}}\right)$, the previous marginal $q_{i}$ times the relevant tax factors.

Using representative tax rates from the 1990s, the personal tax on disbursements, $T_{D}$, is approximately $33 \%$; and the effective personal gains tax rate, $T_{C G}$, is about $14 \%$ (or half of the statutory rate of $28 \%$, assuming that the marginal investor is tax-exempt half the time). This implies that the estimated marginal $q$ should be approximately 0.78 times the theoretical optimal value of $1.0 .^{2}$ The deviation of a firm's estimated marginal $q$ from this benchmark value is used as an indicator of the efficiency of the firm's capital budgeting decisions. More generally, during this period the marginal investor would have faced effective tax rates such that $T_{D} \geq T_{C G} \geq 0$ and the upper bounds on $T_{D}$ and $T_{C G}$ were $33 \%$ and $28 \%$, respectively, so a reasonable range of the tax adjustment would be from 0.78 to 1.00 . Accordingly, we conduct all empirical tests using both estimated benchmark marginal $q$ 's, 0.78 and 1.00 .

2. It may not be realistic to gauge the impact from all possible biases. Durnev et al. (2004) used a nonlinear technique to estimate this benchmark to be in the range $0.755-0.780$, which is consistent with the back-of-the-envelope estimate detailed above and used herein. 


\subsection{EFFICIENCY OF CAPITAL BUDGETING AND INTERNAL INFORMATION SHARING}

We use four complementary measures to proxy for firms' internal information sharing. Because we emphasize the overall organizational capabilities of firms, each firm-including all its branches and subsidiariesis treated as an integrated organization.

Our first measure is the self-citation ratio. Trajtenberg et al. (1997) proposed the self-citation measure, defined as "the percentage of citing patents issued to the same assignee as that of the originating patent," to measure the "fraction of the benefits captured by the original inventor." To capture information flows across locations, we also use the nonlocal self-citation ratio, a specific variation of the self-citation measure that tracks the percentage of cross-regional citations within the firm. Third, to capture the importance of interactions among researchers at multiple locations, we measure cross-regional collaborations, the extent of R\&D collaborations across units or geographic locations. The fourth measure of internal information sharing is examiner-imposed self-citations. In a patent application, the inventors are required to report any prior art that the current patent is based on, and then the patent examinerwho is usually an expert in a certain technological area-would impose other citations that he/she believes appropriate. Although an inventor may or may not cite a competitor's patents for strategic reasons (Alcácer and Gittelman, 2006), failing to cite the same firm's prior art is probably due to ineffective communication and coordination inside the firm. Inventors who have self-citations imposed by examiners are either (1) unaware of the internal knowledge stock or (2) unwilling to acknowledge the contribution from colleagues, which may reflect less than harmonious relationships among units. Hence, we calculate the percentage of self-citations that are imposed by patent examiners, and use it as a reverse measure of internal linkages.

There are two features about the four alternative measures that are worth discussion at this point. First, the four measures reflect information sharing from different perspectives, so they are imperfect alternatives and do not replicate each other. Self-citation ratios capture the result of information flow while cross-regional collaborations capture the process that may facilitate information flow. Meanwhile, examiner-imposed self-citations can be affected by the scope of the technologies and the patents' strategic role in the firm (Alcácer and Gittelman, 2006). As shown in the next section, these variables are correlated in the expected directions but the correlation ratios are not terribly high, which confirms our intuition. Second, these measures are based on patents and related information. Patentable technologies are among the most codified or least tacit part of the information set, and 
therefore easier to transfer across locations than other tacit knowledge. Hence, we may overestimate the true extent of knowledge sharing in firms that rely less on patents and other codified knowledge, which should make it more difficult for us to find statistical significance in our findings.

We use 0.78 and 1.00 as the benchmark marginal $q$ 's, denoted herein as $h$, in the empirical tests in line with the discussion on tax implications presented earlier. Separate analyses are conducted on firms that under- and overinvest, depending on whether $\left(\hat{q}_{i}-h\right)$ is above or below zero; $\left(\hat{q}_{i}-h\right)^{+}$and $\left(\hat{q}_{i}-h\right)^{-}$are used as dependent variables in the two subsamples, respectively. Thus, we examine the relation between the extent of under- or overinvestment and the firm's interunit information sharing using a truncated regression:

$$
\left.\begin{array}{l}
\left(\hat{q}_{i}-h\right)^{+} \\
\left(\hat{q}_{i}-h\right)^{-}
\end{array}\right\}=\alpha+\lambda X_{i}+\eta C_{i}+\omega I_{S I C}+\varepsilon_{i},
$$

where $X$ represents the four alternative variables used to measure internal linkages, and $C$ represents the firm-level control variables. $I_{\text {SIC }}$ are industry fixed effects that capture each firm's primary twodigit SIC code. Finally, we assume that the disturbance term, $\varepsilon_{i}$, is normally distributed with zero mean and constant variance $\sigma^{2}$. As in Greene et al. (2009), we use a Saxonhouse (1976) technique to weigh all observations by the inverse of the standard error associated with the estimate of marginal $q$, then use a weighted truncated regression model to conduct separate examinations of under- and overinvesting firms using equation (4). Because the truncated variance is between 0 and 1 , the marginal effect of each variable may be smaller than that of the corresponding coefficient (Greene, 2003). Because $h$ can assume either of two values, 0.78 or 1.00, we estimate equation (4) four times for each set of independent variables - that is, for the under- and overinvesting subsamples defined relative to 0.78 and 1.00 .

\section{Data AND VARiables}

In this section, we report our sample and data sources, as well as variable construction. Details of the marginal $q$ estimation procedure are reported in the appendix.

\subsection{DATA SAMPLE AND SOURCES}

To estimate marginal $q$ we must have reliable numbers on a firm's market value and assets. We use all data that can be matched across three datasets-Center for Research in Security Prices (CRSP)/Compustat 
Merged Database (Compustat), ${ }^{3}$ CRSP Daily Stocks Database (CRSP), and the U.S. Patent and Trademark Office (USPTO) - using the Directory of Corporate Affiliations (DCA) as a link when possible. Our sample period begins with 1993 because this is the first year for which DCA data is available in electronic format. Because our patent data end in 2006, and it may take years for a patent to go through the application pipeline, ending the sample period in 2001 should allow enough of an observation window for innovations to be captured by the patent data. Our marginal $q$ estimates, which form the basis of the dependent variable in the second-stage regressions, are obtained using Compustat data from 1993-2002; and the independent variables in the second-stage regression, firm innovation and controls, are created using data for the years 1993-2001.

To obtain information on each firm's innovation activity, we first match company names in the Compustat data-which are typically parent companies-to the names in the DCA. The purpose is to rely on the affiliation information in the DCA to create a "family tree" for each firm, so that the analyses are conducted at the organizational level, inclusive of all the branches, subsidiaries, and joint ventures in which the firm has a decisive stake. Next, we match the names of all family members to the patent assignees as documented by the USPTO. For those firms without a match in the DCA, we directly match the firm name from Compustat to the patent assignees as documented by the USPTO.

We acknowledge that firms with patenting activities may not represent all multi-unit firms, which potentially introduces two sources of selection bias to our analysis. First, given that R\&D is likely to be one of the most centralized functions in a firm, information sharing may be particularly important in R\&D-intensive firms. Second, to the extent that $R \& D$-intensive firms find it harder to raise external capital because they are more difficult for outsiders to understand and thus value properly, they are more likely to face liquidity constraints, hence a higher estimated marginal $q$. So we may see more underinvesting firms than we would in the general population of firms. However, despite having possibly higher measures of information sharing and of marginal $q$, we believe that these firms are not systematically different from other firms in terms of their reliance on internal coordination. In the semiglobalized world with significant differences across countries (Ghemawat, 2003), centralization is not always the optimal choice;

3. The CRSP data are reported on a calendar year basis, and the Compustat data are reported on a fiscal year basis. To keep consistency across sources, if the firm's fiscal year ends in January-May (June-December), we use the data covering fiscal years 1992-2001(1993-2002). 
the integration-responsiveness framework proposed by Bartlett and Ghoshal (1989) is still highly relevant to today's "high-tech" and "lowtech" firms alike. High-tech wireless telecommunications companies need location-specific investments catering to local customers, while low-tech manufacturers or retailers who count on standardization to achieve lower costs may find intrafirm coordination crucial to their competitiveness. That is, there is no evidence that firms engaged in patenting activities are special in the information-investment relationship we address in this paper.

Several sample filters are used to make sure that the firm's accounting data are stable, and that noisy and extreme values are excluded. Our results are robust to variations in the thresholds. First, we use only U.S.-headquartered, U.S.-incorporated manufacturing firms (i.e., SIC codes 2000-3999) for which five or more consecutive years of data are available from Compustat. When Compustat reports a value as "insignificant" we set it to zero. To avoid duplication, we remove entries for preferred stock, class B stock, and the like by discarding entries whose CRSP Committee on Uniform Security Identification Procedures (CUSIP) issue number begins with numbers other than 10 or 11 .

Second, several criteria are applied to ensure that the equity market variables are reliable. We include only firms with tangible assets of at least $\$ 1$ million to eliminate firms that may not have the financial means to pursue a coordinated R\&D strategy. Meanwhile, we exclude all firm-year observations when a firm's stock was traded on fewer than 60 days per year (slightly above the first percentile of the distribution, or roughly one in every four trading days), share price was less than $\$ 1$, or the estimated average Tobin's $Q$ was above 5.0. Also excluded are firm-year observations in which the firm's value, total assets, or tangible assets changed by more than $300 \%$ in absolute value.

Finally, a firm is included in the sample if and only if it has at least three patents with the USPTO in a 3-year period. Note that this step may introduce selection bias in the sense that not all manufacturing firms file patents. However, we decide to take this step for two reasons. First, innovative firms with significant intellectual assets are the ones facing the most serious coordination challenges. Second, most of the multi-unit firms in the Compustat data are large firms with multiple patents in the sample period, so the threshold is not too discriminating.

This yielded a dataset with 367 firms with estimates of marginal $q$ ranging from -0.37 to 4.21 . Because the extreme estimates of marginal $q$ were both significantly different from the mean and difficult to interpret economically, we exclude from analysis all firms for which the estimated marginal $q$ was more than two standard deviations away from the mean; 
this cost 22 observations. ${ }^{4}$ We also included only those firms for which there were two or more other firms also in their industry as measured using the two-digit SIC industry code. The resultant dataset contains 342 manufacturing firms in 16 two-digit SIC industries.

The 342 firms in the sample collectively generated 182,203 patents in the sample period, with annual patent output ranging from one to 2,865 for each firm. We rely on the front-page information on the patent applications to identify the detailed address of every single inventor. Following the innovation literature (e.g., Chung and Alcácer, 2002; Singh, 2008), a region is defined as a state in the United States or a country in the rest of the world. This generates 139 unique regions in our sample, including all 50 U.S. states, Washington D.C., Puerto Rico, and 85 foreign countries. The number of locations with R\&D activities ranges from 1 to 55 .

\subsection{VARIABLES}

We follow the Durnev et al. (2004) procedure to construct the dependent variable, marginal $q$. On average, the mean estimated marginal $q$ is 0.94 , suggesting that firms overinvest relative to the theoretical benchmark marginal $q, 1.0$, but not the tax-adjusted benchmark marginal $q, 0.78$ (see Table I). What interests us is the significant variation around the mean (from -0.16 to 2.19 ), which we try to explain using the degree of information sharing inside the firm.

To calculate the self-citation ratio for each patent in our sample, we pull out all the patents that have cited a focal patent after its grant date, and examine whether the assignees belong to the same firm. The ratio of self-citations to the total number of citations is considered the self-citation ratio of the focal patent, and is averaged at the firm level. Because we are interested in firms as integrated organizations, any citations among affiliated organizations are considered self-citations. Consistent with the literature, the average self-citation ratio in our sample is $14.0 \%$, and the number drops to $2.4 \%$ if we only consider selfcitations that occur across intrafirm units located in different regions (i.e., the nonlocal self-citation ratio).

Next, patents with inventors from at least two different regions are considered the result of cross-regional collaborations. We then divide

4. Nineteen of these 22 observations were firms with high estimated marginal $q^{\prime}$ s (i.e., underinvesting firms). It is unclear why we did not observe a symmetric distribution of outlier marginal $q^{\prime}$ s. We do not know if this reflects internal problems such as poorly functioning information sharing channels or external problems such as greater financial constraints. It may stem from our sample selection criterion whereby we include only firms with patenting activities during the time period, and high-tech firms tend to face bigger challenges in obtaining external financing. 


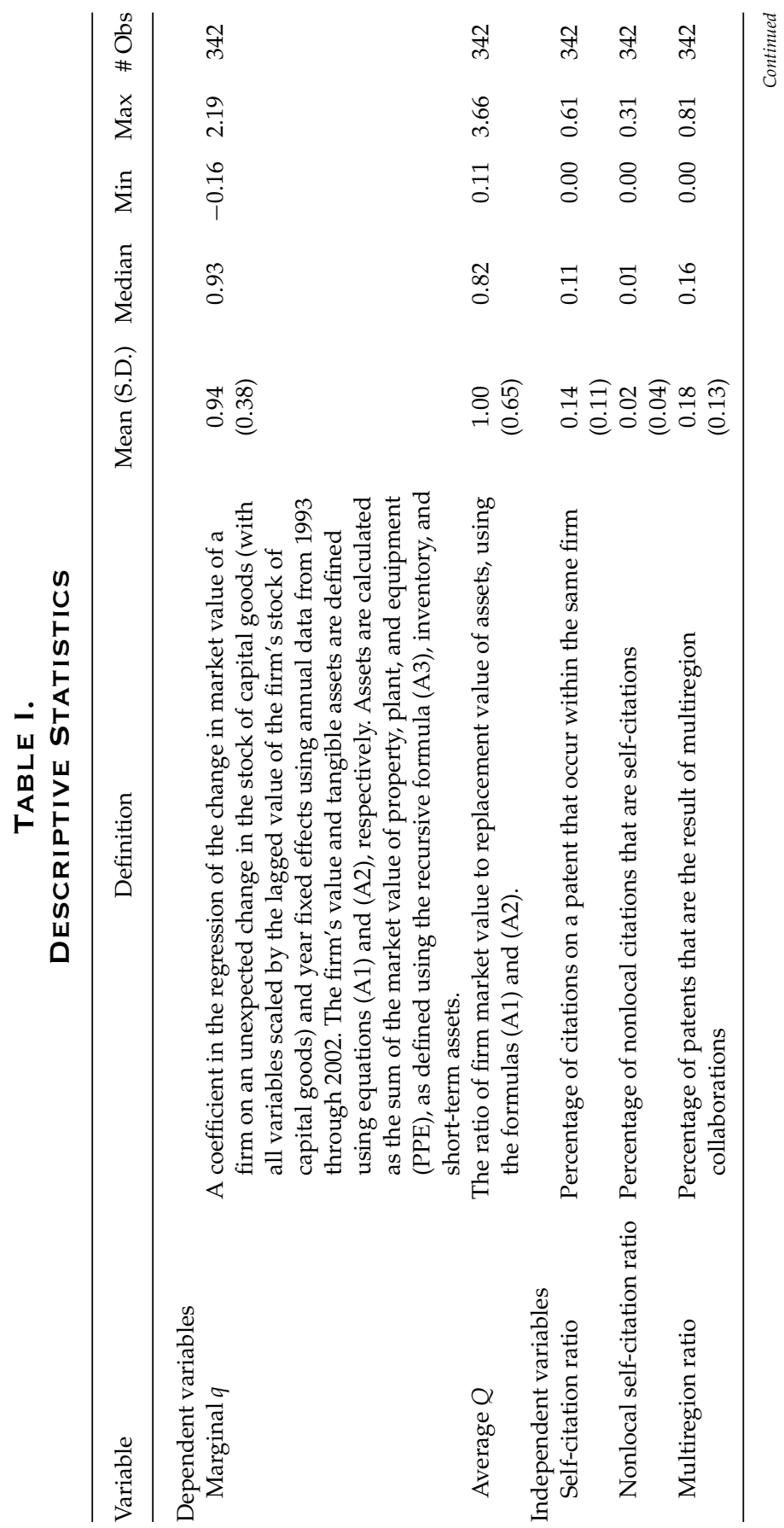


the number of such patents by the total number of patents filed by each firm in each year. It turns out that $17.7 \%$ of the patents are the result of cross-regional collaborations, and despite significant cross-industry variations, this percentage generally increases over time.

The variable examiner-imposed self-citations is calculated for a reduced sample of patent citations. Because the information on examinerimposed versus inventor-listed citations was not available until January 1,2001 , patents granted before that date are removed from the sample. For each focal patent, we divide the number of examiner-imposed selfcitations by the number of all self-citations. $48.0 \%$ of the citations are imposed by examiners. Examiner-imposed citations constitute a large percentage among self-citations as well as all citations, but the ratio of examiner-imposed self-citations has a much higher variance across firms.

We include a series of firm-level variables as controls. First, making sound investment decisions is particularly challenging when the firm's R\&D activities are geographically dispersed. Therefore, we also count the number of regions where the firm has innovative activities. ${ }^{5}$ Controlling for the number of regions is important for another reason. Because all our independent variables reflect aspects of cross-regional ties, they are likely to be correlated with the firm's geographic dispersion of operations. We want to make sure that the internal linkage variables do not just pick up the effects of globalization on market capitalization. For robustness checks, we also use the number of countries in which a firm has innovative activities in order to differentiate more cleanly between firms that conduct innovation at multiple places within an individual country and firms that conduct innovation in multiple countries. ${ }^{6}$

Second, firm size matters. Larger firms are likely to have greater internal financing capabilities, and thus are less constrained by capital when seeking valuable investment projects. However, larger firms tend to face more challenging coordination tasks. They also may have explored most of the profitable investment opportunities and are therefore more likely to overinvest (Jensen, 1986). Firm size is measured as the log of average property, plant, and equipment (PPE) over the time period. Because we are examining innovating firms, we also use the logarithm of the total number of patents that a firm filed in the past 3 years to reflect its overall innovation clout, and use the average number

5. Admittedly, the geographic dispersion of R\&D may well be endogenous, determined by the firms' globalization strategies and their intrinsic organizational capabilities. Addressing the choice of organizational structure is beyond the scope of this paper.

6. Because U.S. firms are not required to disclose overseas revenues or sales, it is not feasible to use accounting based measures to proxy accurately for a firm's multinationality. 
of citations received by each patent to reflect the value of inventions in every sample firm.

Firms' financial conditions also may affect their budgeting decisions. Firms with high cash flow may be more prone to overinvest (Jensen, 1986), while firms with low cash flow may conserve resources for future usage (Himmelberg et al., 2002). Cash flow is measured as the ratio of the sum of income before extraordinary items and depreciation and amortization to tangible assets. We also control for leverage, which is measured as the ratio of the sum of long-term debt and current liabilities to total assets. Although highly leveraged firms may face greater financing constraints and have less leeway to invest because of the bankruptcy threat (Myers, 1977), they also may be subject to greater corporate governance oversight and therefore make more valueenhancing investments (Jensen, 1986). In robustness tests we also use liquidity, the difference between current assets and current liabilities divided by tangible assets, to depict the firm's current financial standing. Finally, we control for corporate industrial diversification. Diversified firms are more likely to be cash rich and have internal capital markets of their own (Stein, 1997). Yet, diversified firms are also more complex and present greater agency and information asymmetry problems to managers and investors. ${ }^{7}$ Firm diversification is measured as the average number of different two-digit segments that are reported in Compustat Industry Segment Data (SSIC2). Although this measure is a noisy proxy of firm diversification, it remains the best choice available in many circumstances and is used widely in the literature (e.g., Linck et al., 2008).

In addition, industry-specific characteristics may cause firms in certain industries to make more or less efficient capital budgeting decisions systematically. Two-digit industry fixed effects, $S_{\text {SIC }}$, are therefore included in our analysis of capital budgeting decisions. Moreover, macroeconomic factors may cause marginal $q$ to be estimated with greater noise in some years. This concern is addressed through the use of year fixed effects and random coefficient estimation of marginal $q$. Table I lists the definitions and univariate statistics for the abovementioned variables, and Table II reports the correlation matrix. In Table III we present the industry composition of firms in the dataset.

7. Admittedly, diversification is not the only, or best, proxy for firm complexity. For example, Blanchard and Kremer (1997) construct a complexity index based on the input-output table across industries. However, this complexity index is estimated at the industry level and will be automatically dropped out when we add the industry dummy. We acknowledge our data constraints, which prevent us from constructing a complexity index to capture the firm heterogeneity we hope to examine in this paper. 


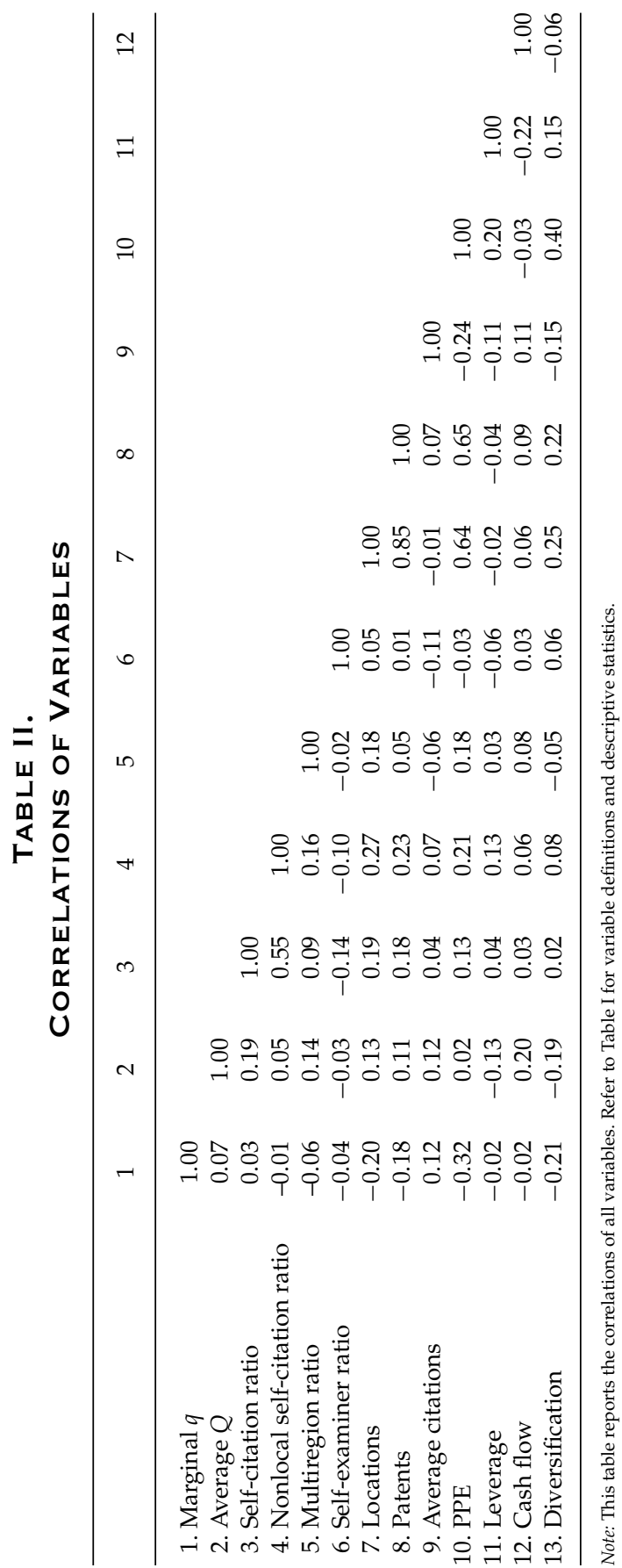


TABLE III.

INDUSTRY COMPOSITION OF FIRMS IN DATASET

\begin{tabular}{|c|c|c|c|}
\hline $\begin{array}{l}\text { Two-Digit } \\
\text { SIC Code }\end{array}$ & $\begin{array}{l}\text { Industry } \\
\text { Name }\end{array}$ & $\begin{array}{l}\text { Number of } \\
\text { Firms }\end{array}$ & $\begin{array}{l}\text { Mean Estimated } \\
\text { Marginal } q\end{array}$ \\
\hline 20 & Food and kindred products & 15 & 0.87 \\
\hline 22 & Textile mill products & 6 & 1.00 \\
\hline 25 & Furniture and fixtures & 8 & 0.86 \\
\hline 26 & Paper and allied products & 19 & 0.88 \\
\hline 27 & Printing, publishing and allied industries & 7 & 0.71 \\
\hline 28 & Chemicals and allied products & 49 & 0.92 \\
\hline 29 & Petroleum refining and related industries & 10 & 0.75 \\
\hline 30 & Rubber and miscellaneous plastics products & 12 & 1.04 \\
\hline 32 & Stone, clay, glass, and concrete products & 6 & 0.90 \\
\hline 33 & Primary metal industries & 12 & 0.71 \\
\hline 34 & $\begin{array}{l}\text { Fabricated metal products, except } \\
\text { machinery and transportation equipment }\end{array}$ & 18 & 0.80 \\
\hline 35 & $\begin{array}{l}\text { Industrial and commercial machinery and } \\
\text { computer equipment }\end{array}$ & 52 & 0.96 \\
\hline 36 & $\begin{array}{l}\text { Electronic and other electrical equipment } \\
\text { and components, except computer } \\
\text { equipment }\end{array}$ & 44 & 0.97 \\
\hline 37 & Transportation equipment & 33 & 0.97 \\
\hline 38 & $\begin{array}{l}\text { Measuring, analyzing, and controlling } \\
\text { instruments; photographic, medical and } \\
\text { optical goods; watches and clocks }\end{array}$ & 44 & 1.08 \\
\hline 39 & Miscellaneous manufacturing industries & 7 & 0.98 \\
\hline
\end{tabular}

Notes: This table reports the number of firms in our dataset in each two-digit SIC code classification. We exclude from analysis all industries in which we obtain estimated marginal $q$ 's for fewer than three firms.

The best-represented industry is "industrial and commercial machinery and computer equipment" (two-digit SIC code 35) with 52 firms.

\section{RESULTS}

It is unclear a priori whether information-sharing channels would have a symmetric effect on the efficiency of capital budgeting among underand overinvesting firms. Essentially, there are two possible mechanisms affecting the relationship between capital budgeting decisions and information sharing. On the one hand, the inefficiency in firms' capital budgeting decisions may stem entirely from information asymmetry. In that case, we would observe a large margin of error with symmetry on the over- and underinvestment sides, and a pooled analysis of all sample firms would be in order. On the other hand, the inefficiency may be due to managers not knowing their lack of information and 
TABLE IV.

DESCRIPTIVE STATISTICS FOR UNDERAND OVERINVESTING FIRMS

\begin{tabular}{|c|c|c|c|c|c|c|}
\hline & $\begin{array}{c}\text { Firms } \\
\text { for which } \\
\hat{q}_{i}>0.78\end{array}$ & $\begin{array}{c}\text { Firms } \\
\text { for which } \\
\hat{q}_{i} \leq 0.78\end{array}$ & $\begin{array}{l}T \text {-Test } \\
\text { of the } \\
\text { Means }\end{array}$ & $\begin{array}{c}\text { Firms } \\
\text { for which } \\
\hat{q}_{i}>1.00\end{array}$ & $\begin{array}{c}\text { Firms } \\
\text { for which } \\
\hat{q}_{i} \leq 1.00\end{array}$ & $\begin{array}{l}T \text {-Test } \\
\text { of the } \\
\text { Means }\end{array}$ \\
\hline Marginal $q$ & $\begin{array}{c}1.14 \\
(0.28)\end{array}$ & $\begin{array}{c}0.55 \\
(0.18)\end{array}$ & $23.77^{* * *}$ & $\begin{array}{c}1.29 \\
(0.25)\end{array}$ & $\begin{array}{c}0.69 \\
(0.22)\end{array}$ & $22.56^{* * *}$ \\
\hline Locations & $\begin{array}{c}7.00 \\
(8.04)\end{array}$ & $\begin{array}{c}8.37 \\
(9.48)\end{array}$ & -1.34 & $\begin{array}{c}5.76 \\
(6.45)\end{array}$ & $\begin{array}{c}8.66 \\
(9.62)\end{array}$ & $-3.34^{* * *}$ \\
\hline PPE & $\begin{array}{c}5.75 \\
(1.91)\end{array}$ & $\begin{array}{c}6.45 \\
(1.85)\end{array}$ & $-3.28^{* * *}$ & $\begin{array}{c}5.49 \\
(1.90)\end{array}$ & $\begin{array}{c}6.35 \\
(1.85)\end{array}$ & $-4.17^{* * *}$ \\
\hline Diversification & $\begin{array}{c}1.63 \\
(0.78)\end{array}$ & $\begin{array}{c}1.83 \\
(0.93)\end{array}$ & $-1.98^{* *}$ & $\begin{array}{c}1.59 \\
(0.75)\end{array}$ & $\begin{array}{c}1.78 \\
(0.89)\end{array}$ & $-2.06^{* *}$ \\
\hline
\end{tabular}

Notes: This table describes the basic characteristics of firms that under- or overinvest. The table reports means, with standard deviations in parentheses.

behaving as if they knew. For example, for firms with parallel operations in multiple countries, information sharing will significantly increase efficiency in the overinvesting camp but not in the underinvesting one. This asymmetric effect justifies separate analyses of the under- and overinvesting firms.

In Table IV, we compare the main characteristics of over- and underinvesting firms, and find that they are systematically different from each other. The overinvesting firms are significantly larger in terms of assets, and they are more diversified geographically and industrially. We therefore decide to examine these two groups of firms separately.

The results of separate analyses of the efficiency of capital budgeting decisions of under- and overinvesting firms are reported in Tables V and VI. If a particular measure of internal coordination has a symmetric effect on these two groups, then it would have opposite signs in the analyses (e.g., negative in Table V and positive in Table VI). However, if a particular measure has the same effect on all firms-for example, leading to lower levels of investment across the board-then it would have the same sign in both subsamples and yet have different interpretations.

\subsection{IMPACT OF INTERNAL COORDINATION AND COMMUNICATION}

We first explore the connection between capital budgeting and overall self-citation ratios. We then zoom in on the self-citations that happen 


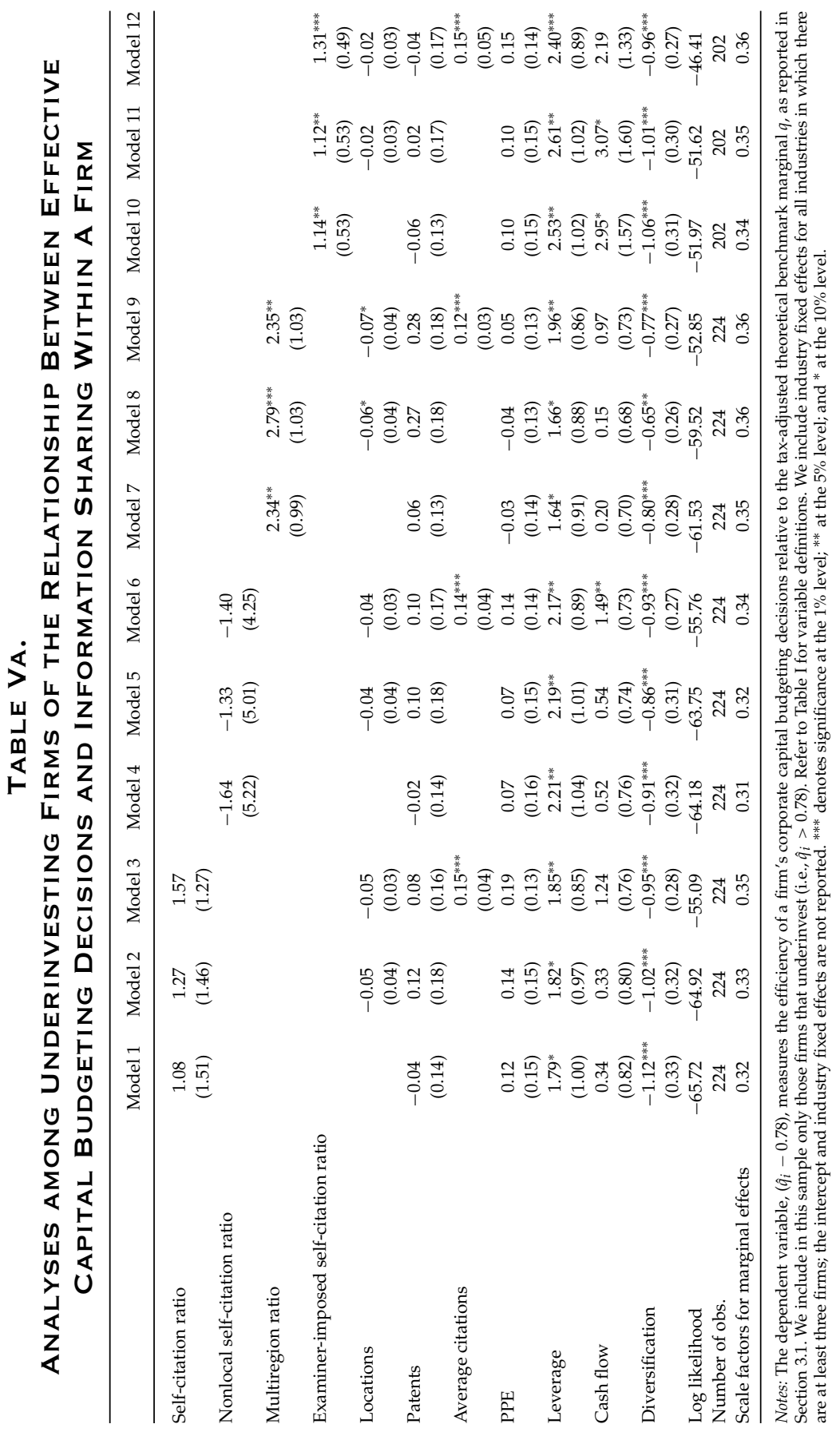




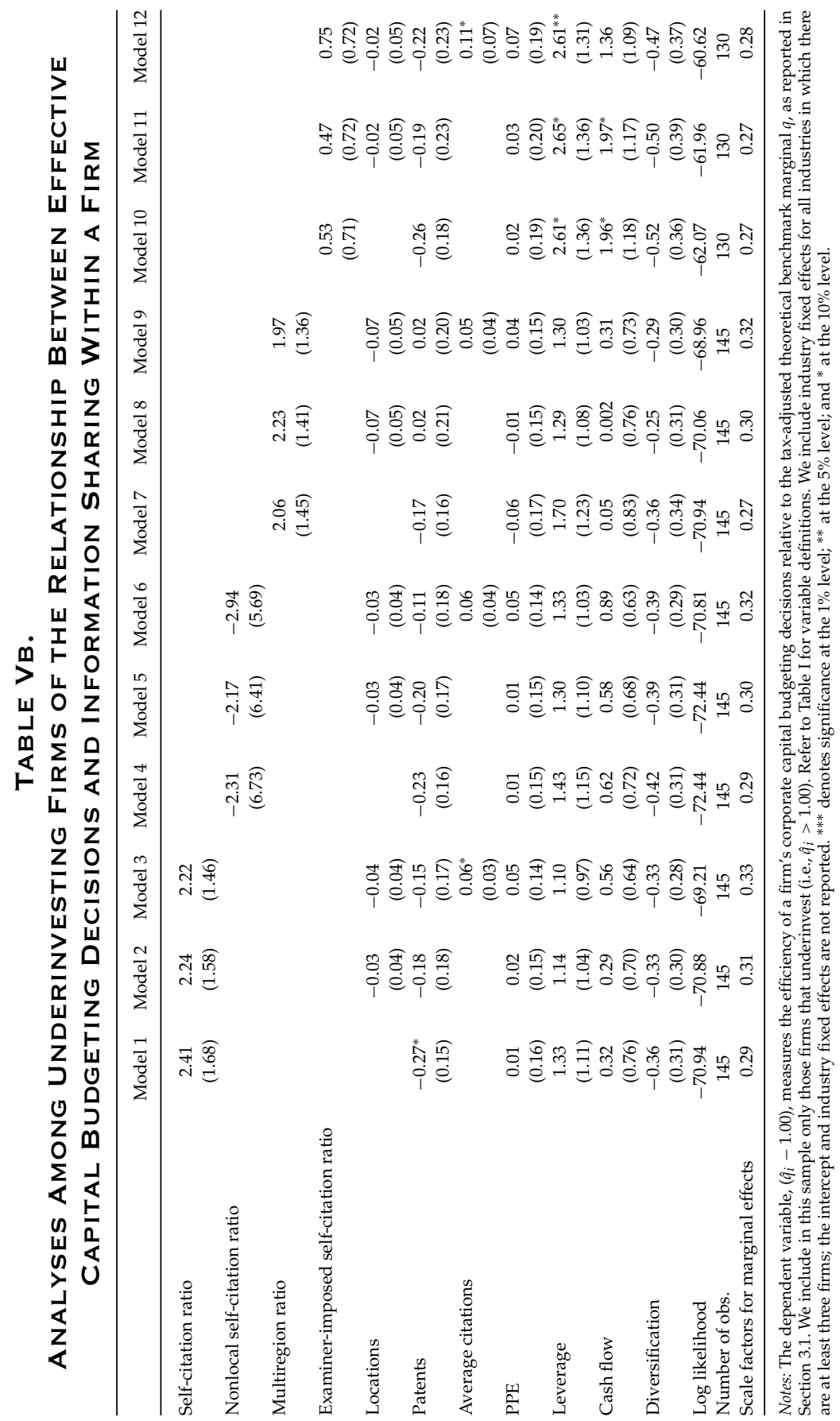


across geographic locations, and use nonlocal self-citation ratio as our key independent variable. Next, we examine the link between value-enhancing capital budgeting decisions and R\&D collaborations among inventors from multiple regions as well as examiner-imposed self-citations. For each of our focal independent variables we run three sets of empirical tests versus each of the two benchmark marginal $q^{\prime}$ s, 0.78 and 1.00. In each set we examine (1) a baseline model using the focal variable, (2) an expanded version including also the number of locations with patenting activities, and (3) a fuller version in which we also control for the average citations received by each patent. ${ }^{8}$ Results for the underinvestment sample defined against the tax-adjusted benchmark marginal $q$ 's of 0.78 and 1.00 are presented in Tables $\mathrm{Va}$ and $\mathrm{Vb}$, respectively; the comparable charts for the overinvestment sample are presented in Tables VIa and VIb, respectively.

Although the link between efficient capital budgeting and selfcitations is statistically insignificant among firms that underinvest (Tables Va and Vb, Models 1-3), it is mostly significant among firms that overinvest (Tables VIa and VIb, Models 1-3), which suggests that repetitive, wasteful investment is reduced when there is greater information sharing within the firm. Nonlocal self-citations indicate the degree to which innovators within the firm build on technologies developed in other parts of the firm, and higher levels of nonlocal selfcitations could indicate better information sharing. Our examination of overinvesting firms reveals that capital budgeting decisions are more effective when a firm has higher levels of nonlocal self-citations (Tables VIa and VIb, Models 4-6). The result is stronger after we control for the number of locations in the firm.

As with the broad self-citation measure, nonlocal self-citation ratio has an insignificant impact on capital budgeting among underinvesting firms (Tables $\mathrm{Va}$ and $\mathrm{Vb}$, Models 4-6). One possible explanation is that the geographically dispersed corporate units (e.g., subsidiaries) are more substitutes rather than complements for each other. When units are substitutes, better information sharing could reduce redundant investments. When units are complements, better information sharing may encourage value-enhancing investments to take advantage of the complementary resources scattered in the firm. We observe more support for the hypothesis of substitutive units.

Among firms that overinvest, interpersonal collaboration across regions turns out to be an effective means of reducing coordination costs and strengthening information sharing in geographically dispersed

8. We run all tests separately among under- and overinvesting firms defined separately versus the two benchmark marginal $q^{\prime}$ s, 0.78 and 1.00 . Thus, two rounds of tests, where each round includes 2 sets of three models, yield a total of 12 sets of results. 


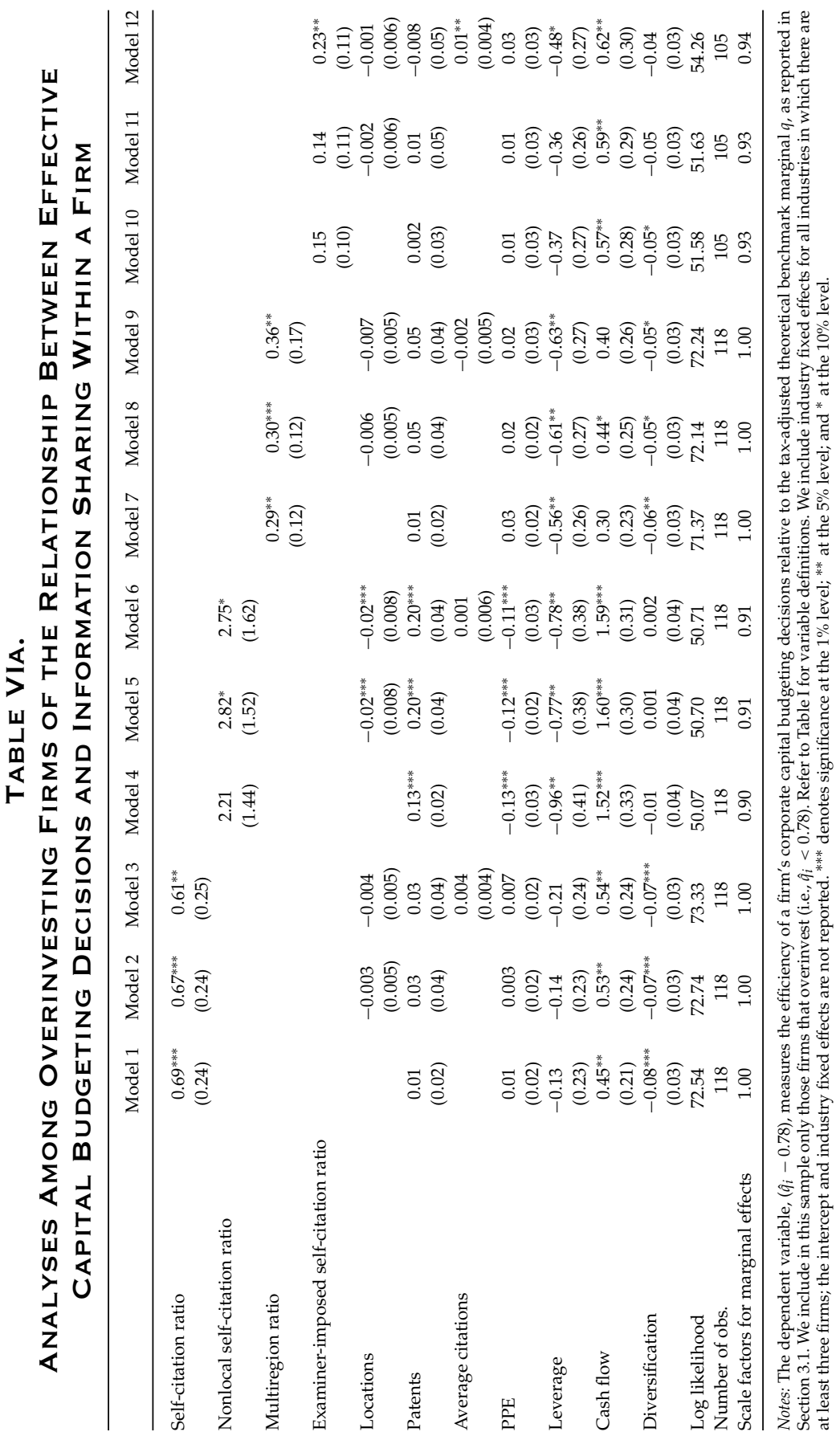




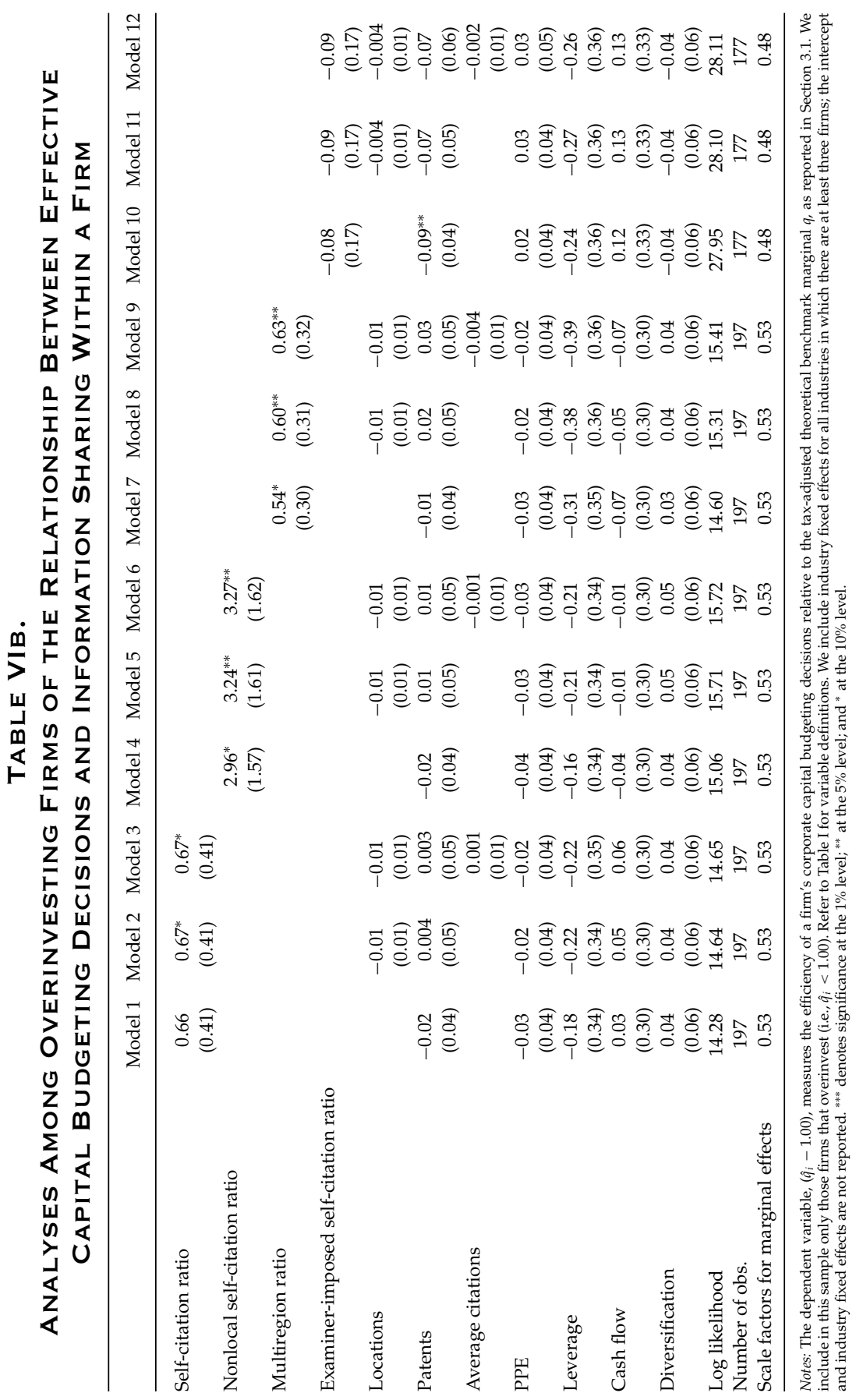


organizations (Tables VIa and VIb, Models 7-9). We find that firms make more value-enhancing capital budgeting decisions with higher proportion of $R \& D$ conducted in multilocation teams; this directly parallels the results reported earlier for the nonlocal self-citation ratio. We also find that among firms that underinvest, the efficiency of their capital budgeting decisions is inconsistently affected by multiregional collaboration on patents. When we evaluate the efficiency of firms' capital budgeting decisions versus the tax-adjusted benchmark marginal $q$ of 0.78 , we find that the efficiency is worsened by such multiregional collaboration (Table Va, Models 7-9) but we find no relationship when we evaluate efficient capital budgeting decisions versus the no tax benchmark marginal $q$ of 1.00 (Table $\mathrm{Vb}$, Models 7-9). This result injects a degree of nuance into how we can interpret our results. It may be the case that extensive cross-regional collaborations, while facilitating information sharing within the firm, also inhibit the firm's integration into the local economy (Zhao and Islam, 2008). This limits the subsidiaries' access to local resources or local market opportunities, thus forgoing valuable investments that should have happened. Therefore, we see that the multiregion ratio is positive and statistically significant in nearly all tests, among both under- and overinvesting firms.

Finally, as mentioned earlier, the percentage of self-citations imposed by patent examiners can be interpreted as a reverse measure of internal information sharing; it reveals the degree to which innovators are unaware of their colleagues' R\&D activities. Of course, this is based on the assumption that the patent examiner knows exactly what should have been listed as prior art and acts objectively. Because this measure is available only for 2001 onward, we examine a smaller number of firms in this set of regressions (307 vs. 342 in our other tests). This result is statistically significant in only 4 of the 12 cases we examine (Tables Va, Vb, VIa, and VIb, Models 10-12). It shows that all firms invest less when they have higher levels of examiner-imposed selfcitations. This results in less efficient capital budgeting decisions for underinvesting firms and more efficient capital budgeting decisions for overinvesting firms, which is counterintuitive. In other words, firms that underinvest leave good projects unexplored while firms that overinvest encounter speed bumps and invest less. One may argue that firms with high levels of examiner-imposed self-citations are not the most resourceful in organizing their global R\&D activities, which suppresses the overall level of $R \& D$ investments. 


\subsection{CONTROL VARIABLES}

Although geographic dispersion could drive up coordination costs, there is evidence that multinational firms make more efficient capital budgeting decisions (Greene et al., 2009) and have stronger managerial skills (Bloom and Van Reenen, 2007; Bloom, Sadun, and Van Reenen, 2011). Further, Brown and Medoff (1989) found that larger, more complex firms may be able to recruit and retain higher-quality employees. Thus, it is not surprising that we find no relationship between the efficiency of a firm's capital budgeting decisions and the number of locations where a firm conducts R\&D. Also, we generally observe no relation between the efficacy of corporate capital budgeting decisions and firm size.

Firms that conduct more R\&D may have more centralized organizational structures. On the other hand, they may face more information asymmetry between managers and investors, who find it difficult to evaluate effectively the intrinsic value of the firm's innovations. Such firms are also more likely to face liquidity constraints and have to rely on internal cash flows to finance investments. We find only limited evidence (Tables $\mathrm{Vb}$ and $\mathrm{VIa}$ ) that firms make more effective capital budgeting decisions when they have more patents.

Firms may have widely cited patents because they (1) have the resources to engage in cutting-edge technologies, (2) are more visible, and (3) are more aggressive in defending their intellectual property, prompting other firms to cite their patents diligently. On the one hand, such patents may represent the successful completion of larger innovation projects that require greater managerial oversight. On the other hand, such projects could signal the presence of a large bureaucratic organization facing greater coordination challenges. We find significant evidence that among firms that underinvest, large citations are associated with worse capital budgeting decisions (Tables $\mathrm{Va}$ and $\mathrm{Vb}$ ).

Weaker capital budgeting decisions are consistently and significantly associated with leverage, regardless of whether the firm underor overinvests (Tables $\mathrm{Va}, \mathrm{Vb}$, and VIa). For firms that underinvest, leverage may lead to additional supervision by external monitors and thus exacerbate the underinvestment situation. For firms that overinvest, high leverage may have resulted from excessive capital spending by the firm. Although leverage may signal the presence of external monitors, higher levels of cash flow may make internal monitors more important. We find that capital budgeting decisions are weakly improved by higher cash flow (Tables Va, Vb, and VIa). Investment efficiency and industrial diversification appear to be weakly 
related, mainly among underinvesting firms. Among those firms that overinvest we do not observe a consistent relationship between efficient capital budgeting and industrial diversification. Other control variables were statistically insignificant in all tests.

\subsection{IMPLICATIONS}

Despite the obvious differences among the four alternative measures of information sharing, we find two consistent results. First, intrafirm information sharing helps improve firms' capital budgeting efficiency. Second, the effects are asymmetric between over- and underinvesting firms. This is useful for us to tease out the specific mechanisms behind the data.

If the information barriers within firms make it difficult to make appropriate investment decisions, and the managers are aware of such difficulties, then a firm's investment level should be randomly distributed around the optimal level as the managers make their best bets. Accordingly, better information sharing should reduce the margin of error for both over- and underinvesting firms in a symmetric fashion. Our empirical results do not support this scenario.

Instead, we find that better information sharing consistently reduces overinvestment but has little effect on underinvestment, which suggests that lack of information sharing led to inefficient investments in the firm. In other words, the managers either underestimated intrafirm information barriers, or did not take them into consideration when making investment decisions. And because our study is focused on geographic diversification rather than industry diversification, most of the subsidiaries are horizontally differentiated. ${ }^{9}$ In such circumstances, information barriers lead to more redundant investments than forgone opportunities.

\section{AVERAge Q-Complementary EVIDENCE}

Unlike marginal $q$, average Tobin's $Q$, the ratio of firm market value to firm replacement value, reflects investors' valuation of the firm. Hayashi (1982) showed that with constant returns to scale and perfect competition, marginal $q$ and average $Q$ should be equal. If information sharing not only affects the quantity, but also raises the quality or profitability of the investments, then we would expect a positive association between intrafirm coordination and Tobin's $Q$.

9. We calculate the technological proximity across subsidiaries following Jaffe (1986), and find the mean distances within firms are much smaller than those across firms, even in the same industry. 
We run four sets of tests of the following model

$$
Q_{i t}=\alpha+\lambda X_{i t}+\eta C_{i t}+\omega I_{S I C}+\delta_{t} P_{t}+\varepsilon_{i t} \text {, }
$$

where $X$ represents the four alternative independent variables used to measure internal linkages, and $C$ represents the firm-level control variables. $I_{S I C}$ are industry fixed effects that capture each firm's primary two-digit SIC code, and $P_{t}$, a series of year fixed effects, are also included to reflect the economic environment. Finally, we assume that the disturbance term, $\varepsilon_{i}$, is normally distributed with zero mean and constant variance $\sigma^{2}$.

When we conducted our earlier tests where marginal $q$ formed part of the dependent variable, the dependent variable was estimated over years $1 \ldots T$ and independent variables were the average value per firm for the years $0 \ldots T-1$. Because average $Q$ can be estimated directly for each year, we now can use $T$ observations for each firm in estimating equation (5). Our dataset of 342 firms contains 224 underinvesting firms and 118 overinvesting firms but we use simultaneously up to 2,663 observations on these 342 firms when examining variation in average $Q$, excluding only those observations for which we have missing data.

Our results from estimation of equation (5) are shown in Table VII. These results complement and mirror our earlier findings regarding marginal $q$ : firm valuation is higher when firms engage in innovation activity that reflects stronger internal coordination and communication. Thus, average $Q$ is significantly higher when firms cite their own patents, cite patents developed by colleagues in other locations, and develop patents with researchers in multiple locations. Similarly, average $Q$ is significantly lower when examiner-imposed self-citations are higher. Although the number of locations is not significantly associated with the marginal $q$ measure, average $Q$ seems to be higher when firms develop patents in more locations, a finding that is consistent with the Morck and Yeung (1991) finding that investors value multinationality if the firm possesses valuable intangible assets. Investors also attach a premium to firms that develop more widely cited patents, which proxy for firm-specific knowledge and intangible assets.

A second, potentially related robustness test is based on Wurgler (2000). Wurgler estimates a country's investment elasticity by measuring the sensitivity of investment to value-added across industries. An analogous measure in our context would reveal how swiftly capital flows to the correct unit within a firm. Unfortunately, to obtain the firm-level estimates of elasticity, we need unit-level data that we do not have. Instead, we create a measure similar to Wurgler's betweenyear component of investment elasticity by regressing the growth in firm assets on the growth in firm value over the years. As we have 


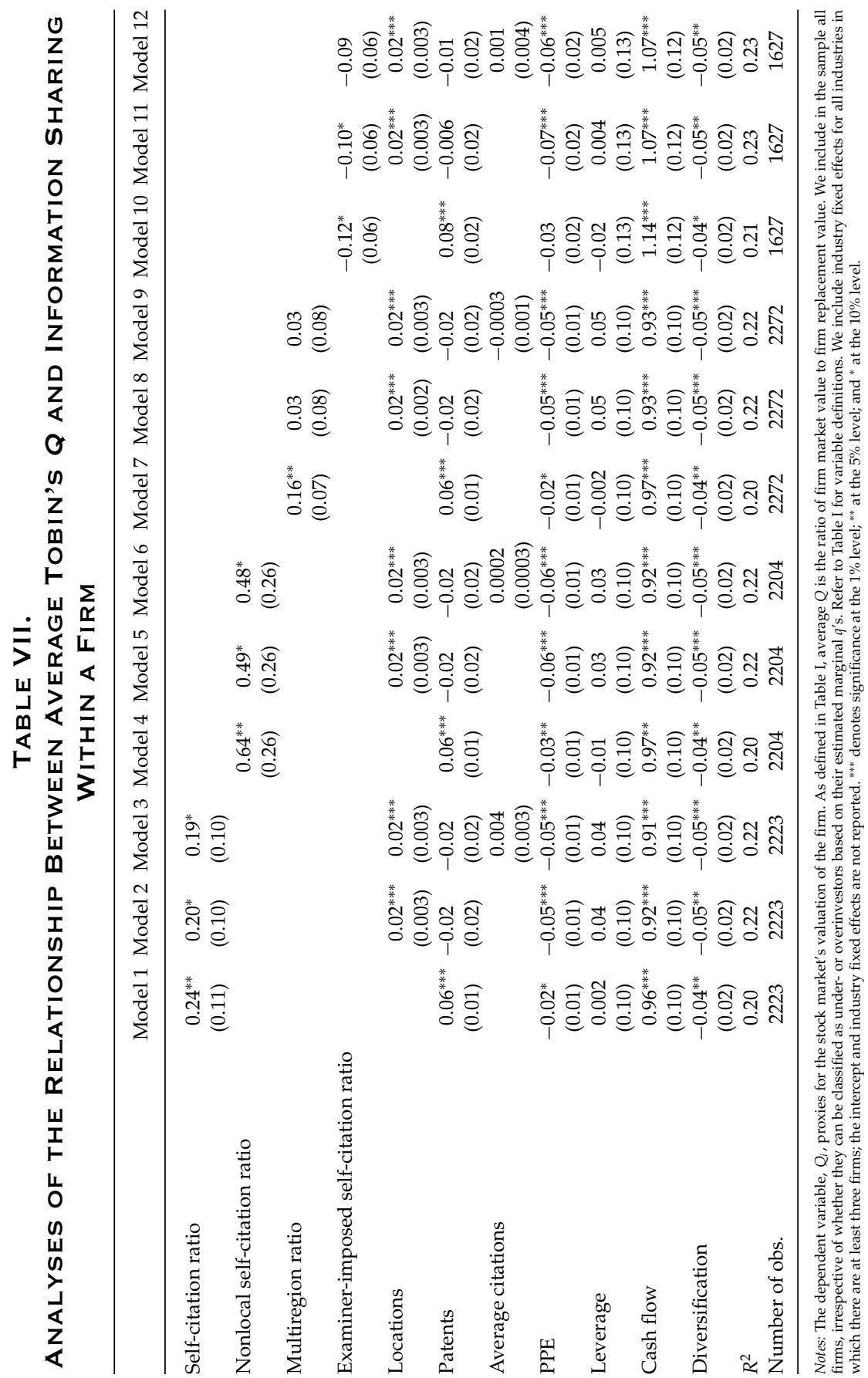


only 5-10 observations per firm, our estimated investment elasticities are very noisy; just 24 of the 343 estimated elasticities are statistically significant. We find that among those firms with negative investment elasticities, firms respond better to market value changes when they have higher self-citation ratios and lower levels of examiner-imposed self-citations; this is consistent with the results reported in Tables Va and VI. Unfortunately, the other results are mostly insignificant, which is probably due to the small numbers of observations used in the firststage estimation of the elasticity.

\section{CONCLUSION}

Firms are increasingly conducting business on a global basis and developing resources at different geographic locations. The additional agency and information asymmetry problems arising from such organizational structures often make it difficult for managers to make efficient corporate capital budgeting decisions. We focus on firm heterogeneity in the degree of internal information sharing, and examine whether the efficiency of corporate capital budgeting decisions is associated with stronger internal linkages.

Using marginal Tobin's $q$ to measure the efficiency of corporate capital budgeting decisions and four alternative variables to measure firms' internal information sharing, we find consistent evidence that firms with (1) higher internal citations, (2) frequent citations across subsidiaries, (3) extensive use of interunit collaborations, and (4) smaller percentage of examiner-imposed self-citations are more likely to avoid inefficient investments from the corporation's perspective. In addition, by linking the same variables to average Tobin's $Q$, we find that better internal coordination is also positively associated with the overall valuation of the R\&D-active firms in our sample.

This study contributes to the economics and finance literature by looking into the firm and identifying the sources of heterogeneity in firms' capital investment efficiency (Greene et al., 2009). Specifically, efficiency in capital investment not only depends on the external environment for information (Durnev et al., 2004), but also relates to internal coordination and information sharing. Our study also contributes to the management literature by showing that intrafirm coordination is important not only for certain strategic goals such as corporate innovation (Singh, 2008), but also for the overall financial performance of firms.

Admittedly, there may be other factors in firms' capital budgeting decisions that cannot be fully incorporated into this study. For future research, it would be interesting to have a closer look at the benefits 
and costs of strong internal linkages, and analyze whether firms with different strategic imperatives or cost structures would choose specific levels of interunit integration, which, in turn, affects the efficiency of corporate budgeting. Another promising avenue to explore is the nature of relationships among the divisions and subsidiaries in the firm. Hansen (2002) suggests that a proper understanding of effective interunit knowledge sharing in a multi-unit firm should take into consideration relatedness in knowledge content among business units. For instance, if investment inefficiencies are due to managers' ignorance of internal coordination problems, then managers in a horizontally diversified firm may be more likely to make poor investments while such managers in a vertically diversified firm may underinvest, missing opportunities that reside in complementary assets within the firm. Understanding the nature of firm diversification will help us disentangle the specific mechanisms underlying the inefficiencies and thus provide better insights for practitioners.

\section{Appendix}

When estimating marginal $q$, the terms $V_{i, t}$ and $A_{i, t}$ are rewritten as:

$$
\begin{aligned}
& V_{i, t}=P_{t}\left(C S_{i, t}+P S_{i, t}+L T D_{i, t}+S D_{i, t}-S T A_{i, t}\right), \\
& A_{i, t} \equiv K_{i, t}+I N V_{i, t}+P_{t} S T A_{i, t},
\end{aligned}
$$

where

$C S_{i, t}=$ the market value of the outstanding common shares, estimated as the number of common shares outstanding (CRSP's SHROUT) multiplied by the end of fiscal year price (CRSP's PRC).

$P S_{i, t}=$ the estimated market value of preferred shares outstanding (Compustat's Data19) over the Moody's Baa preferred dividend yield. ${ }^{10}$

$L T D_{i, t}=$ estimated market value of long-term debt (Data9).

$S D_{i, t}=$ book value of short-term debt, estimated as debt in current liabilities (Data34), the total amount of short-term notes and the current portion of long-term debt that is due in 1 year, less the total amount of short-term notes (Data206).

10. These data are available online at http://research.stlouisfed.org/fred/data/ irates/baa. 
$S T A_{i, t}=$ book value of short-term assets (Data4). $S T A_{i, t}$ is included in the estimation of firm assets, $A_{i, t}$, in order to reflect the possibility of corporate spin-offs or divestitures.

$P_{t}=$ inflation adjustment using the GDP deflator. ${ }^{11}$

$K_{i, t}=$ estimated market value of PPE, which is calculated using current and historical data on capital spending (Data7).

$I N V$ = estimated market value of inventories, calculated using total inventory (Data3) and LIFO reserve (Data240). When a firm uses FIFO accounting, inventory is Data3. However, when a firm uses LIFO accounting, inventory is Data3 + Data240.

In equation (3) we estimate $D_{i, t-1}$, disbursements to investors, as the product $d_{i, t} V_{i, t-1}$, with $d$ capturing total cash disbursements, which are estimated as the sum of cash dividends on common and preferred stock (Data21 and Data19), purchases of common and preferred stock (Data115), ${ }^{12}$ and interest expense (Data15).

The market value of PPE is calculated using a recursive algorithm because historical cost accounting does not adjust properly for inflation. All PP\&E figures are converted to 1983 dollars, ${ }^{13}$ and we assume straight-line depreciation of $10 \%$ per annum. PP\&E in year $t+1$ is PP\&E from year $t$ less $10 \%$ depreciation plus current capital spending, denoted $\Delta X_{i, t+1}$, which is deflated to 1983 dollars. We convert the data to 1983 dollars using $\pi_{t}$, the fractional change in the seasonally adjusted producer price index (PPI) for finished goods published by the U.S. Department of Labor, Bureau of Labor Statistics. ${ }^{14}$ More generally, we use the recursive equation:

$$
K_{i, t+1}=(1-\delta) K_{i, t}+\frac{\Delta X_{i, t+1}}{\prod_{\tau=0}^{t+1}\left(1+\pi_{\tau}\right)} .
$$

When fewer than 10 years of historical observations are available per firm, we begin the calculation with the first available year of data. We exclude all firms for which we are unable to obtain at least five historical observations. This procedure is necessary because historical cost accounting can cause firm valuations of PP\&E to be inaccurate if simple deflators are used to adjust for inflation.

Average $Q$ is estimated as $Q_{i t} \equiv \frac{V_{i t}}{A_{i t}}$.

11. These data are available online at http://research.stlouisfed.org/fred/data/ ppi/ppifgs.

12. This is to capture share repurchases.

13. If the first observation for a firm is a different year, we use that as the firm's base year instead.

14. These data are available online at http://research.stlouisfed.org/fred/data/ ppi/ppifgs. 


\section{REFERENCES}

Alcácer, J. and M. Gittelman, 2006, “How Do I Know What You Know? Patent Examiners and the Generation of Patent Citations," Review of Economics and Statistics, 88(4), 774-779.

— and M. Zhao, 2011, "Local R\&D Strategies and Multi-Location Firms: The Role of Internal Linkages," Management Science, forthcoming.

Audretsch, D.B. and M.P. Feldman, 1996, "R\&D Spillovers and the Geography of Innovation and Production," American Economic Review, 86(3), 630-640.

Bartlett, C.A., and S. Ghoshal, 1989, Managing Across Borders: The Transnational Solution, Boston, MA: Harvard Business School Press.

- and -1990 , "The Multinational Corporation as an Inter-Organizational Network," Academy of Management Review, 15(4), 603-625.

Blanchard, O. and M. Kremer, 1997, "Disorganization," Quarterly Journal of Economics, 112(4), 1091-1126.

Bloom, N. and J. Van Reenen, 2007, "Measuring and Explaining Management Practices Across Firms and Countries," Quarterly Journal of Economics, 122(4), 1351-1408.

- and -2011 , "Americans do I.T. Better: US Multinationals and the Productivity Miracle," American Economic Review, forthcoming.

Brown, C. and J. Medoff, 1989, "The Employer Size-Wage Effect," Journal of Political Economy, 97(5), 1027-1059.

Buckley, P. and M. Casson, 1976, The Future of the Multinational Enterprise, London: Homes \& Meier.

Chung, W. and J. Alcácer, 2002, "Knowledge Seeking and Location Choice of Foreign Direct Investment in the United States," Management Science, 48, 1534-1554.

Cockburn, I. and R. Henderson, 1998, "Absorptive Capacity, Coauthoring Behavior, and the Organization of Research in Drug Discovery," Journal of Industrial Economics, 46(2), 157-182.

Desai, M.A., F. Foley, and J.R. Hines Jr., 2004, “A Multinational Perspective on Capital Structure Choice and Internal Capital Markets," Journal of Finance, 59(6), 2451-2488.

Durnev, A., R. Morck, and B. Yeung, 2004, "Value Enhancing Capital Budgeting and Firm-Specific Stock Returns Variation," Journal of Finance, 59(1), 65-105.

Feinberg, S. and A.K. Gupta, 2004, "Knowledge Spillovers and the Assignment of R\&D Responsibilities to Foreign Subsidiaries," Strategic Management Journal, 25, 823-845.

Ghemawat, P., 2003, "Semiglobalization and International Business Strategy," Journal of International Business Studies, 34(2), 138-152.

Graham, J.R., M. Lemmon, and J. Wolf, 2002, “Does Corporate Diversification Destroy Value?" Journal of Finance, 57, 695-720.

Greene, W.H. 2003, Econometric Analysis, 5th ed., Upper Saddle River, NJ: Prentice Hall.

, A.S. Hornstein, and L.J. White, 2009, "Multinationals Do It Better: Evidence on the Efficiency of Corporations' Capital Budgeting," Journal of Empirical Finance, 16(5), 703-720.

Gupta, A.K. and V. Govindarajan, 2000, "Knowledge Flows Within Multinational Corporations," Strategic Management Journal, 21, 473-496.

Hall, Bronwyn H., A.B. Jaffe, and M. Trajtenberg, 2002, "The NBER Patent Citation Data File: Lessons, Insights and Methodological Tools," in Jaffe and Trajtenberg, eds., Patents, Citations, and Innovations, Cambridge, MA: MIT Press.

,-- , and 2005, "Market Value and Patent Citations," Rand Journal of Economics, 36, 16-38.

Hansen, M.T., 2002, “Knowledge Networks: Explaining Effective Knowledge Sharing in Multiunit Companies," Organization Science, 13(3), 232-248. 
Hayashi, F., 1982, “Tobin's Marginal q and Average q: A Neoclassical Interpretation," Econometrica, 50, 213-224.

Henderson, R.M. and I. Cockburn, 1994, “Measuring Competence: Exploring Firm Effects in Pharmaceutical Research," Strategic Management Journal, 15, 63-84.

Himmelberg, C.P., R. Glenn Hubbard, and I. Love, 2002, "Investor Protection, Ownership, and the Cost of Capital," Working Paper, Columbia University.

Jaffe, A.B., 1986, “Technological Opportunity and Spillovers of R\&D: Evidence from Firms' Patents, Profits, and Market Value," American Economic Review, 76(5), 984-1001.

—, M. Trajtenberg, and R. Henderson, 1993, "Geographic Localization of Knowledge Spillovers as Evidenced by Patent Citations," Quarterly Journal of Economics, 434, 578-598.

- - and M.S. Fogarty, 2000, “The Meaning of Patent Citations: Report on the NBER/Case-Western Reserve Survey of Patentees," NBER Working Paper, No. 7631.

Jensen, M.C., 1986, "Agency Costs of Free Cash Flows, Corporate Finance and Takeovers," American Economic Review, 76(2), 323-329.

John, K., L. Litov, and B. Yeung, 2008, “Corporate Governance, Risk-Taking and Growth," Journal of Finance, 63(4), 1679-1728.

Kogut, B. and U. Zander, 1992, "Knowledge of the Firm, Combinative Capabilities, and the Replication of Technology," Organization Science, 3(3), 383-397.

Lahiri, N., 2010, "Geographic Distribution of R\&D Activity: How does it Affect Innovation Quality?" Academy of Management Journal, 53(5), 1194-1209.

Linck, J.S., J.M. Netter, and T. Yang. 2008, "The Determinants of Board Structure," Journal of Financial Economics, 87(2), 308-328.

Morck, R. and B. Yeung, 1991, "Why Investors Value Multinationality?" Journal of Business, 64(2), 165-187.

Economics, 33(1-2), 41-56.

Myers, S.C., 1977, “Determinants of Corporate Borrowing," Journal of Financial Economics, $5(2), 147-175$.

- and N.S. Majluf, 1984, "Corporate Financing and Investment Decisions when Firms Have Information that Investors do not Have," Journal of Financial Economics, 13(2), 187-221.

Saxonhouse, G.R., 1976, "Estimated Parameters as Dependent Variables," American Economic Review, 66(1), 178-183.

Shleifer, A. and R.W. Vishny, 1989, "Managerial Entrenchment: The Case of ManagerSpecific Investments," Journal of Financial Economics, 25(1), 123-139.

Singh, J., 2008, "Distributed R\&D, Cross-Regional Ties and Quality of Innovative Output," Research Policy, 37(1), 77-96.

Stein, J., 1997, “Internal Capital Markets and the Competition For Corporate Resources," Journal of Finance, 52(1), 111-133.

Szulanski, G., 1996, "Exploring Internal Stickiness: Impediments to the Transfer of Best Practices Within the Firm," Strategic Management Journal, 17, 27-43.

Trajtenberg, M., R. Henderson, and A.B. Jaffe, 1997, “University versus Corporate Patents: A Window on the Basicness of Invention," Economics of Innovation and New Technology, 5(1), 19-50. Also in: Jaffe, A. and M. Trajtenberg, eds., 2002, Patents, Citations, and Innovations, Cambridge: MIT Press.

Wurgler, J. 2000, "Financial Markets and the Allocation of Capital," Journal of Financial Economics, 58, 187-214.

Zhao, M., 2006, "Conducting R\&D in Countries with Weak Intellectual Property Rights Protection," Management Science, 52(8), 1185-1199.

— and M. Islam, 2008, "Cross-Regional Ties Within Firms: Promoting Knowledge Flow or Discouraging Knowledge Spillover?" Working Paper, Ross School of Business, University of Michigan. 